Kohl: a Journal for Body and Gender Research Vol. 6, No. 2 (Fall 2020)

\title{
Living a Double Life
}

Neja 
I am a 24-year-old cisgender queer woman, who has a bachelor's degree in law; in other words, I'm a very smart intersectional unicorn. I'm OK with this today, but things were a lot different just a few years back.

I have spastic cerebral palsy, 4th stage, and need assistance with just about every single activity. I identify as "not straight." I choose not to limit myself with any of the letters in the acronym of the LGBT+ community, because doing so fills me with a level of anxiety I cannot describe. I have never been good with fitting into a box, be it due to my disability ${ }^{1}$ or my sexual orientation. Identifying myself with any of the letters has always made me feel as if I needed to live up to an unattainable standard. After years of soul searching, I decided to let go of societal expectations of what I should be. But let me start from the beginning.

I have been wheelchair bound since birth and l've grown up having to fight the preconception of what makes a handicapped person. I guess the generic idea is that a person with a disability is someone who sits in a chair in oversized clothes (because these are of course the easiest to put on), who is uneducated, has no prospects, no longing for beauty, absolutely no desire for sex, and most of all does not deserve to be desired by anyone. You won't be surprised to hear me say I wasn't like that. From a very young age I followed all the fashion trends, I spent most of my time hanging out with friends who were not handicapable like me. I was a straight-A student, naturally curious about everything and everyone around me. I never left the house without make-up on and snug trendy clothes. I also watched what I ate, because I felt that letting myself eat what I wanted would ultimately only make me fit the bill of the archetypal handicapped person that the society has tried so hard to pin on me. Doing all that somehow made me feel normal and in control of the narrative. It lessened all the anxiety and depression I was feeling at the time.

And so began my years-long battle with my mental health - one I can't be sure will ever cease or pause. At about 18 , I finally came to terms with my handicap and I stopped obsessing over how to convince other people that I was normal. I also became an activist for the rights of people with disabilities, or as I prefer it, different abilities.

Throughout my disability-related activism I decided to address every topic but one, my sexuality or anything related to sex, because I felt that people would not take it seriously in any shape or form no matter how hard I tried. And I also did not take myself seriously in that regard because I thought that maybe they were right, that I really was an asexual person with a broken body. On the other hand, I also did not want to be fetishized, because that made me feel even worse, so I just omitted talking about anything related to sexuality.

Shortly after my 18th birthday I moved out of my parents' house and started studying law. During my teenage years I only liked or "dated" cis straight men, but after l'd moved out, begun living on my own, and broken free from my homophobic family, I met somebody who changed my outlook. I fell in love

\footnotetext{
${ }_{1}^{1}$ Throughout my essay I will intentionally be mixing the terminology because I personally cannot agree with any of them a hundred per cent. I am aware it's a touchy subject, so out of respect for everyone I will be using all of the semi-acceptable terminology, keeping in mind that personal views and do not invalidate anyone else's feelings or opinions on the topic.
} 
with a nonbinary person. As if that situation wasn't hard enough, they were also my assistant. Two worlds collided and nothing was ever going to be the same. I had so much anger and confusion inside of me. It started with anger due to the fact that it wasn't a cis guy I was spending my energy on. More than that, as my assistant, they saw me naked on daily bases. I learned to pretend that was okay, because I didn't have a choice. Society acts as if seeing someone naked is a big deal. I felt invalidated as a woman because someone I liked had already seen me naked so many times that my body somehow didn't matter anymore. I didn't know how they could still find me attractive after being so used to working as my assistant. The relationship between an assistant and myself is supposed to be free of any sexual tension due to the nature of the job. So feeling all those feelings felt immoral, wrong, and irrelevant. The tension ended up being too much for the both of us and we had a fight in which we expressed all of our feelings (or the lack thereof). After that, they were fortunately able to quit and we didn't talk for a while, which made it better. But that was only the beginning of the battle with my sexuality.

I started battling with self-harm, depression, and anxiety stemming from the fact that I didn't know how to deal with my feelings. I felt there was no point in me being honest with everyone, because I can't be queer, right? At least that's what I have been told. But there was light at the end of the tunnel. I finally had to face up to one fact - I was never going to fit the bill of someone society deems normal, so why would I even try?

After that episode I came to terms with my sexuality, but only privately, and it was honestly a lot easier than coming to terms with my handicap (or maybe it was due to the fact that I was already different because of my disability so adding another layer wasn't that much of a big deal). If you can be a unicorn, you can be an intersectional unicorn, right? When it comes to my friends and my family I came out very selectively. I was keenly aware of the stereotype that depicts people with disabilities as asexual beings, devoid of any carnal desire. Convincing others that I was a straight woman was hard enough, but having them accept that I was not straight was mission impossible. The upshot was that I only came out to a few friends, who I was sure would be supportive and wouldn't doubt my true feelings, because I simply didn't have the energy or the means to make others change their minds. Let's be honest, I barely managed to convince myself of it, struggling to fend off the incessant hum of the society repeating, "you can't be queer, you're handicapped." So, I kept on living my selective closeted existence. But then I started volunteering at a legal clinic set up to help queer youth.

Shortly after starting to volunteer, without a warning, my life almost fell into pieces. In September 2018, I went on an Erasmus+ student exchange to Belgium. It was supposed to be one of the best experiences in my life, but it turned out to be nothing short of a nightmare. The local caregivers who were supposed to help me get on with my daily life simply didn't bother. I spent three months in Belgium and the care I received was so stellar that on some days I was left without food, in bed, or in pain, I was unable to go to the bathroom, and I was just plainly disrespected as a human being. I returned home that December. I subsequently developed severe PTSD, so I turned to the LGBT+ NGO where I was volunteering. I was expecting to be welcomed with open arms. Surely, people who've experienced discrimination first hand would know better than to discriminate, right? Sadly, that wasn't the case. I still wore my hair long back then, and a feminine look has always been a vital part of my identity, because it was a quiet way of resisting the societal idea of a disabled person. Also, as a 
handicapable activist, I would never miss a chance to speak my mind when it came to accessibility and the rights of people with disabilities. Needless to say, my attitude and I didn't go on well with the NGO. I was always looked down upon when I spoke up. When I asked for an accessibility ramp, they simply ignored me. I stopped dressing femininely and I was always conscious about wearing too much makeup or showing up for a meeting in a dress - because apparently dresses are not queer enough. Suddenly, what used to help me feel comfortable every single day now became a source of stress, dread, and alienation. At one point I realised I was no longer standing up for what I believed in. So, I went into another closet, a handicapable one. Trying to shut down a part of my identity took a toll on my mental health. I thought about leaving LGBT+ activism and just locking that part of me away. This would have been easier to hide that hiding my handicap.

I experienced the same trope in my disability activism. I felt like I couldn't talk about my non-normative sexuality and every time I did I would be met with confused looks by handicapable people and non handicapable people alike because they just couldn't understand why I would "want to" live like that. They just couldn't wrap their heads around the fact that it wasn't a matter of choice.

But then one day, purely by chance, I found myself at the London pride parade. I can't explain my feeling when, about 10 minutes into the parade, I saw handicapable queer people there, being out and proud and accepted for everything they are. I started to count them, but I stopped at 100. For the first time I felt lost in the crowd, but at the same time, I have never felt more seen. It was, honestly, the best moment of my existence. That's when I decided I can't give up activism just because others feel I should. First of all, for me, because hiding away in a dark corner has never helped. And secondly, for all the other handicapable queer people, who will come after me, and maybe seeing me own every single part of myself will help them deal with it all, just a little bit. That's all I can ask for. To finish off, even whilst sat down, I will always stand out in a crowd. It's always going to be hard living in two separate worlds, where people don't completely accept my truth for what it is in all its complexity. I will always feel a little bit alone everywhere I go, but maybe that's the beauty of it. Wherever I go, I get to dance to the beat of my own drum, making up rules as I go along. 